\title{
Árboles del Valle Central de Costa Rica: reproducción
}

\section{Carboncillo}

\section{Resumen}

Se presenta una breve descripción del árbol carboncillo (Acacia angustissima (Mill.) Kuntze), e información sobre fenología como base para la recolección de frutos, el manejo de las semillas, la viverización y el proceso de germinación.

Palabras clave: Acacia angustissima (Mill.) Kuntze, fenología, manejo de semillas, viverización, germinación, árboles, Costa Rica.

\section{Abstract}

Trees of the Central Valley of Costa Rica: reproduction. Carboncillo. The following issue presents a brief description about the "carboncillo" tree (Acacia angustissima (Mill.) Kuntze) including information about its phenology which directly relates to fruit recollection, seed treatment, nursery, and germination processes.

Key words: Acacia angustissima (Mill.) Kuntze, phenology, seeds treatments, management at nursery, germination, trees, Costa Rica.

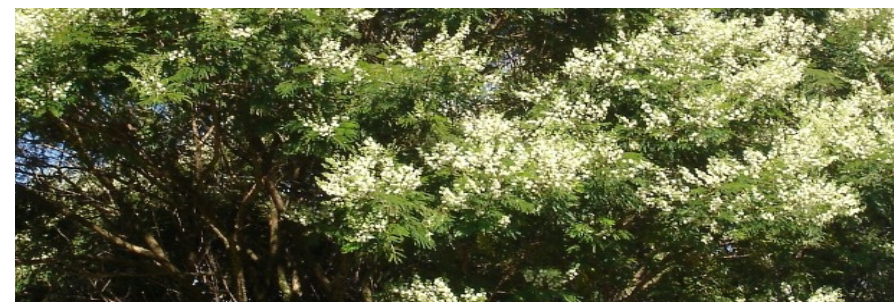

Figura 1. Copa globosa del arbusto carboncillo.

\section{Taxonomía}

Nombre científico: Acacia angustissima (Mill.) Kuntze.

Nombre común: Carboncillo, Acacia de pradera (Geilfus 1989).

Familia: Fabaceae-Mimosaceae

Origen: Nativa

\section{Distribución en el mundo}

Desde el sur de los Estados Unidos hasta Costa Rica. (Geilfus 1989).

\section{Distribución en Costa Rica}

En elevaciones medianas; con climas de húmedos a muy húmedos; frecuentemente en el Valle Central (Holdridge et al. 1997). 


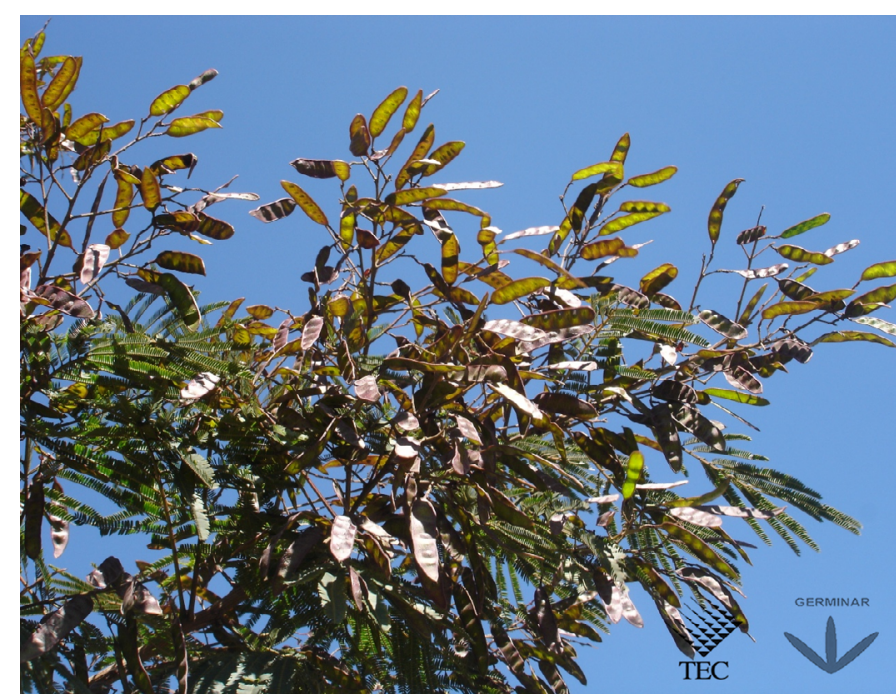

Figura 2. Frutos de carboncillo.

\section{Descripción}

Árbol pequeño tipo arbusto, de copa globosa, esparcida y redondeada. Presenta tallo múltiple y delgado, con ramas delgadas. La corteza es color café - oscuro, lisa, opaca con lenticelas de color claro.

Presenta un follaje caducifolio, sus hojas son compuestas bipinnadas, alternas. Sin espinas, tiene de 6 a 15 pares de pinnas y hasta 60 o más pares de hojuelas por pinna. Nervio principal excéntrico (Holdridge et al. 1997).

Sus flores son llamativas, en inflorescencias terminales color blanco que le confieren a la especie un valor ornamental excepcional.

Produce frutos secos dehiscentes tipo vaina corta (Geilfus 1989), aplanada, muy delgada de hasta $8 \mathrm{~cm}$ de largo y $12 \mathrm{~mm}$ de ancho.

Las semillas son pequeñas aplanadas de color café oscuro, de aproximadamente $3 \mathrm{~mm}$.

\section{Dendrofenocronograma}

Se presenta a continuación información fenológica de carboncillo, para el Valle Central de Costa Rica.

\begin{tabular}{|c|c|c|c|c|c|c|c|c|c|c|c|c|}
\hline \multirow{2}{*}{ Características } & \multicolumn{12}{|c|}{ Meses del año } \\
\hline & E & F & M & A & M & $\mathbf{J}$ & $\mathrm{J}$ & A & s & 0 & $\mathbf{N}$ & D \\
\hline Hojas & & & & & & & & & & & & \\
\hline Flores & & & & & & & & & & & & \\
\hline Frutos verdes & & & & & & & & & & & & \\
\hline Frutos maduros & & & & & & & & & & & & \\
\hline
\end{tabular}

Figura 3. Dendrofenocronograma de carboncillo en la región central de Costa Rica.

\section{Manejo de semilla y viverización}

Los frutos de carboncillo se recolectan de enero a abril. Su madurez se reconoce por su color.

Como tratamiento pregerminativo se coloca la semilla en agua por un periodo de 12 a 24 horas antes de la siembra. En la siembra, las semillas se disponen en forma de puntos en un sustrato a base de tierra más arena, éstas se deben cubrir superficialmente. La germinación se experimenta entre 5 a 14 días después de la siembra. Su porcentaje de germinación, dependiendo de la calidad de la semilla, varía entre un 60 a 84\% (Torres et al. 2011).

Las plántulas se encuentran listas para su repique o transplante, una semana posterior a la germinación, se siembra bajo el sistema de producción en bolsa plástica.

En cuanto al mantenimiento de las plántulas, es recomendable aplicar sombra por un periodo no mayor a los 8 días, así como fertilización química u orgánica una vez que superen los 12 a $15 \mathrm{~cm}$ de altura (Torres et al. 2011).

\section{Proceso de Germinación}

La germinación de carboncillo es epigea, según la siguiente ilustración.

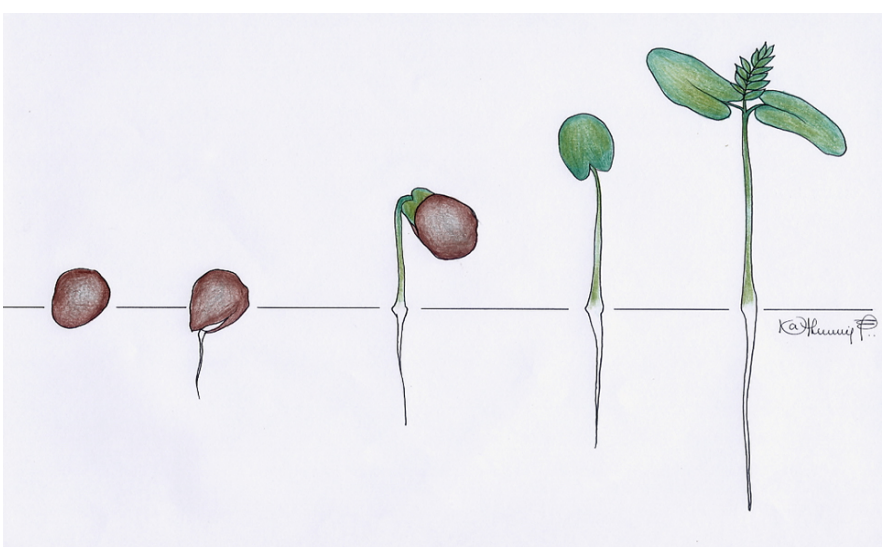

Figura 4. Proceso de germinación de carboncillo.

\section{Referencias}

Geilfus, F.1989. El árbol al servicio del agricultor: Manual de agroforestería para el desarrollo rural. Sto. Domingo, DO, Editorial Santo Domingo. p. 556-557.

Holdridge, L; Poveda, L; Jiménez, Q. 1997. Árboles de Costa Rica. San José, CR, Centro Científico Tropical. Vol. 1. p.142.

Torres, C; Carvajal, D; Rojas, F; Arguedas, M. 2011. Reproducción de especies arbóreas y arbustivas de la región central de Costa Rica. Germinar. (en línea). Cartago, CR, Instituto Tecnológico de Costa Rica. Esc. de Ing. Forestal. Consultado: 20 ene. 2013. Disponible en http://www.tec.ac.cr/sitios/Docencia/forestal/Germinar/ germinar\%202.html 